УДК 630*524.634: 630*561.26: 519.876

\title{
РАНГОВЫЕ РАСПРЕДЕЛЕНИЯ ПАРАМЕТРОВ КРИВЫХ ВЫСОТ ПО ДЕНДРОРЯДАМ РАЗНОВОЗРАСТНОГО СОСНЯКА СИБИРИ \\ (C) 2015
}

П.М. Мазуркин, доктор технических наук, профессор, заведующий кафедрой природообустройства,

академик РАЕ и РАЕН, член Европейской Академии Естествознания

ФГБОУ «Поволжсский государственный технологический университет», Йошкар-Ола (Россия), kaf_po@mail.ru

Введение. В любом лесном древостое растущие деревья находятся между собой в неравновесном состоянии [3-10]. И это состояние можно оценивать на компонентном уровне $[6,7,9]$ экологического баланса $[8,10]$, например, по кривым высот стволов деревьев, расположенных на пробной площади [5]. При этом древостой возмущается по сложным закономерностям с волновыми составляющими как реакция на естественные долговременные воздействия. Волновая теория колебательной адаптации деревьев нами доказана и это в будущем позволит разрабатывать базовые критерии лесопользования [2].

Цель статьи - в продолжение [1] дать методику рангового распределения параметров дендрорядов на примере кривых высот ангарских сосен. Сложные ранговые распределения показывают качество поведения сосняка.

Модель кривой высот. Все иерархические 18 дендрорядов по убыванию кривой высот сосен на пробной площади 1963-4 [1] образовались (табл. 1) по биотехническому закону [1-10]

$$
H_{c}=a_{1} D_{1.3}^{\kappa} a_{2} \exp \left(-a_{3} D_{1.3}^{\kappa} a_{4}\right),
$$

Параметры модели (1) дендрорядов сосняка Сибири

Таблица 1

\begin{tabular}{|c|c|c|c|c|c|}
\hline \multirow{2}{*}{ Ранг } & Дендрометрический & \multicolumn{4}{|c|}{ Параметры биотехнического закона (1) } \\
\cline { 3 - 6 } & ряд сосен & $a_{1}$ & $a_{2}$ & $a_{3}$ & $a_{4}$ \\
\hline 0 & сверхлидеры & 15.23577 & 0.17938 & 0 & 1 \\
\hline 1 & сильнейшие & 3.72378 & 0.66226 & 0.0099096 & 1 \\
\hline 2 & очень сильные & 3.34152 & 0.74259 & 0.031599 & 0.80105 \\
\hline 3 & сильные & 2.85102 & 0.76207 & 0.028927 & 0.79502 \\
\hline 4 & слабонапряженные & 59965963.0 & 4.32542 & 18.65608 & 0.13368 \\
\hline 5 & малонапряженные & $1.47337 \mathrm{e} 8$ & 5.54270 & 20.89217 & 0.14710 \\
\hline 6 & напряженные & $5.13193 \mathrm{e} 8$ & 4.30588 & 20.60887 & 0.12486 \\
\hline 7 & сильнонапряженные & $6.06041 \mathrm{e} 8$ & 4.04959 & 20.52577 & 0.11949 \\
\hline 8 & высокоинтенсивные & $1.24895 \mathrm{e} 8$ & 5.87700 & 21.12994 & 0.15229 \\
\hline 9 & супернапряженные & $1.01280 \mathrm{e} 9$ & 2.32316 & 19.72245 & 0.075883 \\
\hline 10 & начало ослабления & $4.78115 \mathrm{e} 8$ & 3.48861 & 20.02212 & 0.10663 \\
\hline 11 & сопротивляющиеся & $1.34680 \mathrm{e} 8$ & 4.87016 & 20.36289 & 0.13498 \\
\hline 12 & слабеющие & $4.04670 \mathrm{e} 8$ & 2.92613 & 19.87548 & 0.087442 \\
\hline 13 & слабоватые & $2.29354 \mathrm{e} 8$ & 2.65981 & 19.15619 & 0.082480 \\
\hline 14 & слабые деревья & $4.35757 \mathrm{e} 8$ & 0.57397 & 18.88978 & 0.001377 \\
& & & & & 6 \\
\hline 15 & очень слабые & $4.17035 \mathrm{e} 8$ & 0.57645 & 18.93498 & 0.001097 \\
& & & & & 3 \\
\hline
\end{tabular}




\begin{tabular}{|c|c|c|c|c|c|}
\hline 16 & аутсайдеры & 512643.7 & 8.24457 & 20.44165 & 0.18636 \\
\hline 17 & усохшие сосны & 3.22377 & 0.59458 & 0.0003476 & 1.62246 \\
& & & & 1 & \\
\hline
\end{tabular}

где: $H_{c}-$ высота ствола по модельному дереву, м;

$D_{1,3}^{\kappa}$ - диаметр ствола на высоте 1,3 м в коре (для сухостоя без коры), см. $a_{1}$ напряженность роста сосен, м; $a_{2}$ - интенсивность роста; $a_{3}$ - активность; $a_{4}$ интенсивность спада высоты.

Антропогенные воздействия происходят импульсно, поэтому сообщество лесных деревьев не способно реагировать на них адекватно [2].

Долговременная структурно-функциональная динамика лесного фитоценоза не может быть изучена без учета поведения сухостойных деревьев. Они органично вписаны в лесной фитоценоз. Поэтому в таблице 1 к 203 модельным деревьям учитывался дендроряд из 16 сухостойных сосен.

Добротность измерений. Качество статистической выборки таблицы 1 измеряется ранговыми распределениями каждого фактора. Рангами $p$ становятся номера дендрорядов. Фактор влияет на самого себя и монары показывают добротность данных и служит средством для проверки достоверности.

Заметим, - человеческий фактор распределяется, как правило, по простому закону экспоненциальной гибели, в отличие от биотехнического факmopa деревьев, дающего картину сложного взаимодействия между ними в лесу.

Детерминированные закономерности. Общее уравнение для любых факторных отношений, в том числе и для нашего примера, имеет вид

$$
y=b_{1} x^{b_{2}} \exp \left(-b_{3} x^{b_{4}}\right)+b_{5} x^{b_{6}} \exp \left(-b_{7} x^{b_{8}}\right)
$$

где $y$ - показатель; $x$ - объясняющая переменная; $b_{1} . . b_{8}$ - параметры модели (2), получаемые в ходе идентификации в программной среде типа CurveExpert.

В таблице 2 даны значения параметров модели (1), а на рисунках 1 и 2 показаны графики влияния диаметра на высоту по 18 рядам ангарских сосен.

Таблица 2

Параметры уравнения (2) рангового распределения параметров (1) по дендрорядам

\begin{tabular}{|c|c|c|c|c|c|c|c|c|c|}
\hline \multirow{2}{*}{$\begin{array}{l}\text { Параметр } \\
\text { модели (1) }\end{array}$} & \multicolumn{4}{|c|}{ Основной тренд модели (2) } & \multicolumn{4}{|c|}{ Вторая составляющая модели (2) } & \multirow{2}{*}{$\begin{array}{l}\text { Коэфф. } \\
\text { коррел. }\end{array}$} \\
\hline & $b_{1}$ & $b_{2}$ & $b_{3}$ & $b_{4}$ & $b_{5}$ & $b_{6}$ & $b_{7}$ & $b_{8}$ & \\
\hline$a_{11}$ & 15,23572 & 0 & 1,39812 & 0,15099 & 0,000020515 & 3,93842 & 0 & 0 & 1,0000 \\
\hline$a_{12}$ & 1,19107e16 & 9,83468 & 22,27563 & 0,25446 & 0 & 0 & 0 & 0 & 0,3210 \\
\hline$a_{2}$ & 2,42253 & 0 & $-0,021775$ & 1 & 0 & 0 & 0 & 0 & 0,1672 \\
\hline$a_{3}$ & $5,43905 e 8$ & 9,44300 & 21,53153 & 0,25543 & 0 & 0 & 0 & 0 & 0,8701 \\
\hline$a_{4}$ & 1 & 0 & 0,24074 & 1 & $1,46320 \mathrm{e}-37$ & 30,09689 & 0 & 0 & 0,9585 \\
\hline
\end{tabular}



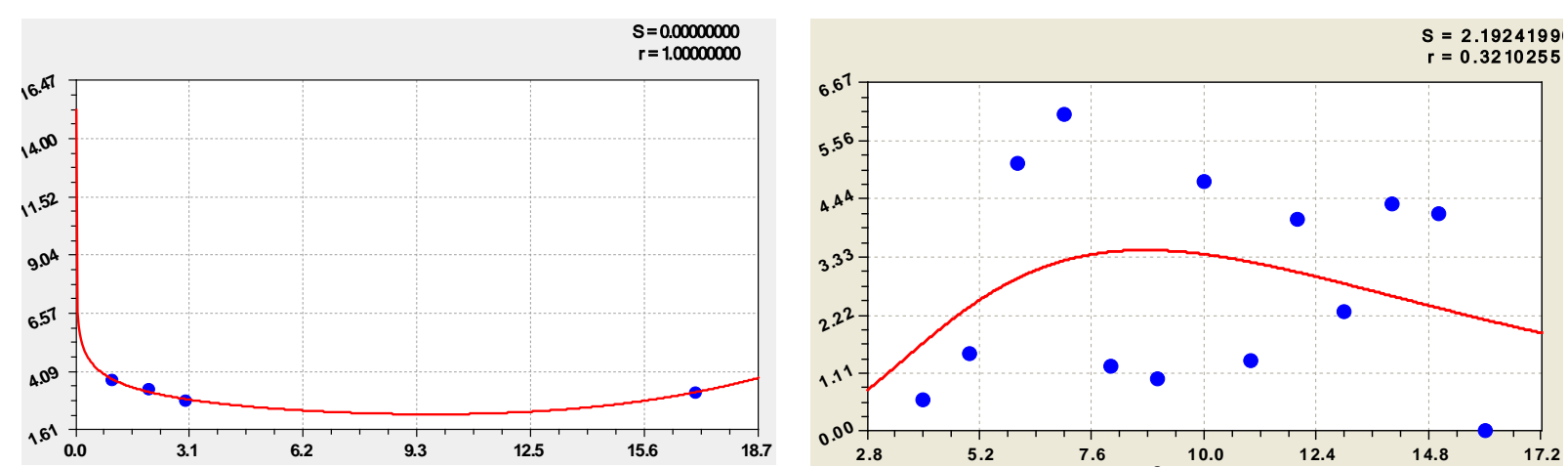

Напряженность лидеров и сухостойных сосенНапряженность $\times 10^{8}$ без лидеров и сухостоя Рисунок 1. Ранговые распределения параметра $a_{1}$ модели (1) по двум частям рядов сосен

По напряженности роста и развития четко выделяются две части рядов сосен: а) это дендроряды 0-4 и ксилоряд 17, который образовался за период 80 лет до 1963 г. рубки сосняка по модельным деревьям; б) дендроряды 5-16 сосен, растущих в высоту с высоким напряжением.

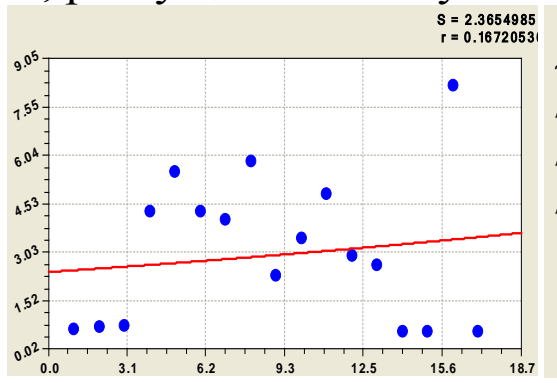

параметр $a_{2}$ модели (1)

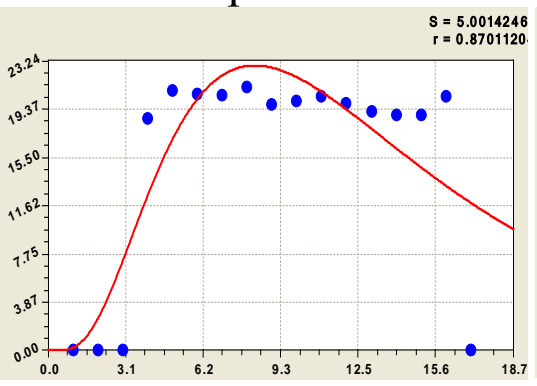

параметр $a_{3}$ модели (1)

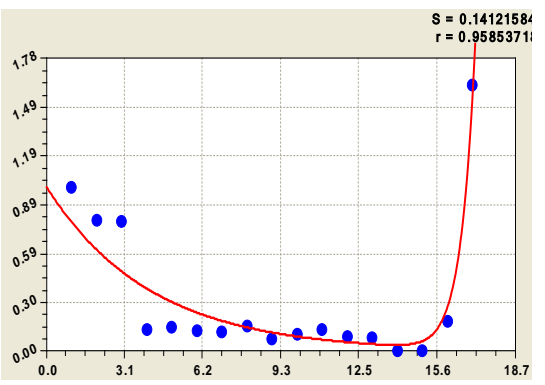

параметр $a_{4}$ модели (1)

Рисунок 2. Ранговые детерминированные распределения параметров модели (1) дендрорядов

Замечательно то, что все три параметра модели (1) $a_{2}, a_{3}$ и $a_{4}$ позволяют охватить по данным таблицы 1 все ранги от 0 до 17. Но активность роста в высоту по закону Лапласа (Ципфа в биологии, Мандельброта в физике и Парето в экономике) по формуле $a_{2}=2,42253 \exp (0,021775 p)$ при условии $p=0,1,2, \ldots, 17$ дает очень малый коэффициент корреляции 0,1672 (в правом верхнем углу рис. 2). Спад роста имеет сильную тесноту связи с коэффициентами корреляции 0,8701 (активность) и 0,9585 (интенсивность).

Закономерности с волнами. Совместный учет тенденций и стохастических составляющих четко предполагает, что вся жизнь лесных деревьев и древостоев протекает по законам волновой адаптации к условиям произрастания. На нарастание амплитуды и частоты возмущения влияет хозяйственная деятельность [2, 6-10]. Лесное хозяйство, не зная волновых закономерностей появления и поведения ядра леса - древостоя, пытается выращивать одновозрастные и одновидовые деревья в посадках. В естественном древостое преобладают симбиотические отношения и поэтому молодые деревца появляются в древостое без конкуренции там, где это нужно всей популяции деревьев.

Нами доказано, что волновая адаптация деревьев происходит по асимметричной вейвлет-функции с переменными амплитудой и частотой колебания 


$$
y=\sum_{i=1}^{m} y_{i}, y_{i}=b_{1 i} x^{b_{2 i}} \exp \left(-b_{3 i} x^{b_{4 i}}\right) \cos \left(\pi x /\left(b_{5 i}+b_{6 i} x^{b_{7 i}}\right)-b_{8 i}\right),
$$

где $y$ - показатель, $i$ - номер составляющей модели (3), $y_{i}$ - составляющая модели (3), x - влияющий фактор, $\pi$ - число «пи», в CurveExpert с 18 знаками после запятой; cos - косинус (удобнее чем синус); $A=b_{1 i} x^{b_{2 i}} \exp \left(-b_{3 i} x^{b_{4 i}}\right)$ - половина амплитуды колебания; $P=b_{5 i}+b_{6 i} x^{b_{7 i}}$ - половина периода колебания; $b_{8 i}$ сдвиг начала волны, рад; $b_{1} . . b_{8}$ - параметры модели (3), определяемые в программной среде CurveExpert в процессе идентификации по выборке измерений.

Напряженность роста сосен по рангам дендрорядов. В таблице 3 даны параметры модели (3) волновой динамики (рис. 3) показателя $a_{1}$ по таблице 1.

В таблице 3 значения параметров уравнений (3) записаны с пятью значащими цифрами, что позволяет сохранить их уровень адекватности. При меньшем количестве значащих цифр сама запись формул их огрубляет.

График на рисунке 3 показывает, что с ранга 4 начинается волнение деревьев по напряженности роста в высоту. Сильное колебание есть в интервале $p=6 . .11$, при этом дендроряды с рангами 5, 8 и 11 имеют примерно одинаковое напряжение роста.

Таблица 3

Параметры волнового уравнения (3) рангового распределения 18 дендрорядов по напряженности $a_{1}$ роста 219 сосен (203 модельных деревьев и 16 сухостоя) в высоту

\begin{tabular}{|c|c|c|c|c|c|c|c|c|c|}
\hline \multirow[t]{2}{*}{ № } & \multicolumn{4}{|c|}{ Амплитуда колебания } & \multicolumn{4}{|c|}{ Полупериод и сдвиг колебания } & \multirow{2}{*}{$\begin{array}{l}\text { Коэфф. } \\
\text { коррел. }\end{array}$} \\
\hline & $b_{1 i}$ & $b_{2 i}$ & $b_{3 i}$ & $b_{4 i}$ & $b_{5 i}$ & $b_{6 i}$ & $b_{7 i}$ & $b_{8 i}$ & \\
\hline 1 & 15,23572 & 0 & 1,39812 & 0,15099 & 0 & 0 & 0 & 0 & \multirow{5}{*}{0,9949} \\
\hline 2 & $2,05150 \mathrm{e}-5$ & 3,93842 & 0 & 0 & 0 & 0 & 0 & 0 & \\
\hline 3 & 7,28111e18 & 12,93977 & 29,67755 & 0,25446 & 0 & 0 & 0 & 0 & \\
\hline 4 & 12,00799 & 15,52465 & 1,86207 & 0,99503 & 1,62693 & $-0,012102$ & 1,00079 & 0,38774 & \\
\hline 5 & $5,20358 \mathrm{e} 7$ & 0,51816 & 0 & 0 & 6,76105 & $-0,19539$ & 1 & 5,25048 & \\
\hline
\end{tabular}

Ряды сосен 12-15 пытаются сохранить высокое напряжение роста, но аутсайдеры ранга 16 резко сбавляют активность роста. После сухостоя с рангом 17 график снова возрастает и, по-видимому, это связано с подростом.
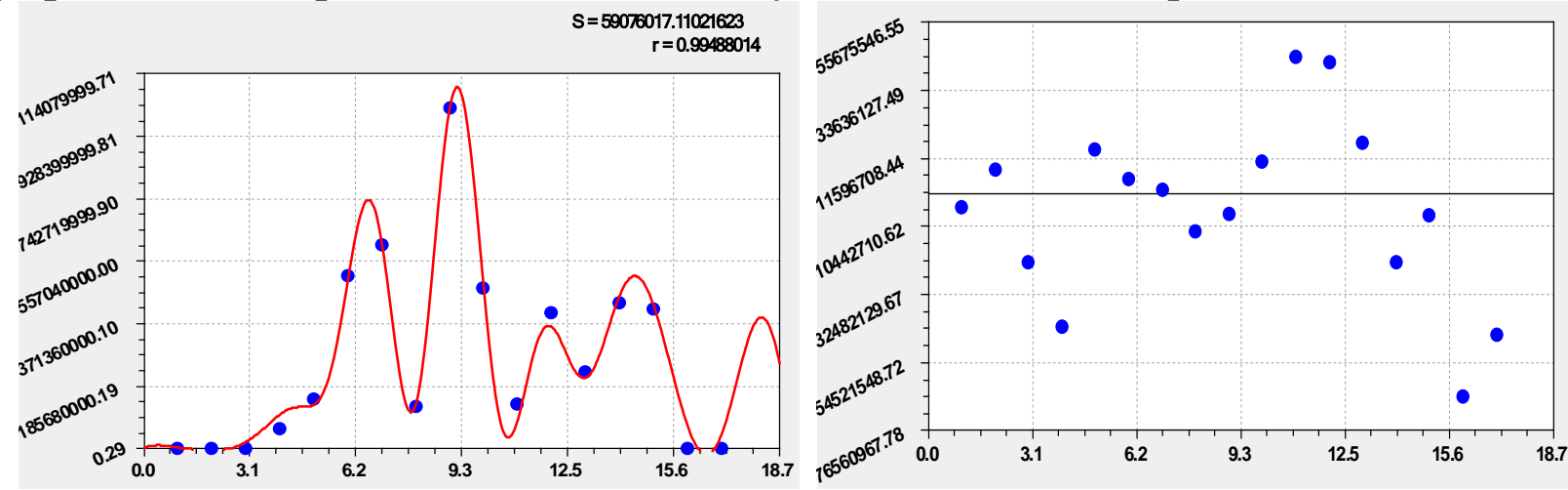

график модели (3) с параметрами из таблицы 3Остатки после модели (3) с пятью членами

Рисунок 3. Ранговые распределения параметра $a_{1}$ модели (1) по всем 18 дендрорядам 
Интенсивность роста сосен по рангам дендрорядов. В таблице 4 даны параметры (3) волновой динамики (рис. 4 и рис. 5) критерия $a_{2}$ по таблице 1.

Таблица 4

Параметры волнового уравнения (3) распределения сосен 18 дендрорядов по интенсивности $a_{2}$ у биотехнического закона (1) роста сосен в высоту

\begin{tabular}{|c|c|c|c|c|c|c|c|c|c|}
\hline \multirow[t]{2}{*}{ № } & \multicolumn{4}{|c|}{ Амплитуда колебания } & \multicolumn{4}{|c|}{ Полупериод и сдвиг колебания } & \multirow{2}{*}{$\begin{array}{l}\text { Коэфф. } \\
\text { коррел. }\end{array}$} \\
\hline & $b_{1 i}$ & $b_{2 i}$ & $b_{3 i}$ & $b_{4 i}$ & $b_{5 i}$ & $b_{6 i}$ & $b_{7 i}$ & $b_{8 i}$ & \\
\hline 1 & 4,87956 & 0 & 0,039035 & 1 & 0 & 0 & 0 & 0 & \multirow{3}{*}{0,9949} \\
\hline 2 & $-4,92188$ & 0 & 0,036475 & 1,91218 & 6,80949 & $-0,0068396$ & 2,09210 & 0,49394 & \\
\hline 3 & $1,26666 \mathrm{e}-7$ & 6,37856 & 0 & 0 & 13,00087 & $-0,37494$ & 1,11339 & $-1,67519$ & \\
\hline 4 & $-0,21675$ & 2,27321 & 0,34324 & 1 & 2,66638 & 0,087434 & 1 & $-2,84464$ & 0,8782 \\
\hline 5 & 0,47558 & 0 & 0,016261 & 1 & 2,69558 & $-0,019049$ & 1,14669 & 1,89277 & 0,7602 \\
\hline 6 & $4,89218 \mathrm{e}-8$ & 67,65390 & 18,62164 & 1 & 2,09973 & $-0,18292$ & 1 & 4,42155 & 597 \\
\hline 7 & $6,43190 \mathrm{e}-22$ & 36,85653 & 3,55983 & 1 & 1,37016 & $-0,016383$ & 1 & 2,52365 & 7811 \\
\hline 8 & $-2,35646$ & 0 & 2,01886 & 1 & 0,60911 & $-0,00097440$ & 1 & 1,47896 & 0,8075 \\
\hline 9 & 0,0060398 & 1,06786 & 0 & 0 & 2,90603 & $6,79918 \mathrm{e}-5$ & 2,73030 & 4,00797 & 0,8941 \\
\hline 10 & $1,02823 e-5$ & 8,32486 & 1,04879 & 0,94044 & 3,88238 & 0,41555 & 1,25821 & $-2,08958$ & 0,8802 \\
\hline
\end{tabular}

Основное трехчленное уравнение было получено в CurveExpert, позволяющей идентифицировать до 19 параметров модели. Из рисунка 4 видно, что импульсные изменения интенсивности роста в высоту есть на рангах 13-17. Этот импульс создает дендроряд аутсайдеров. Умирающие сосны превращаются в сухостой и пытаются повысить интенсивность роста. Но затем погибают.

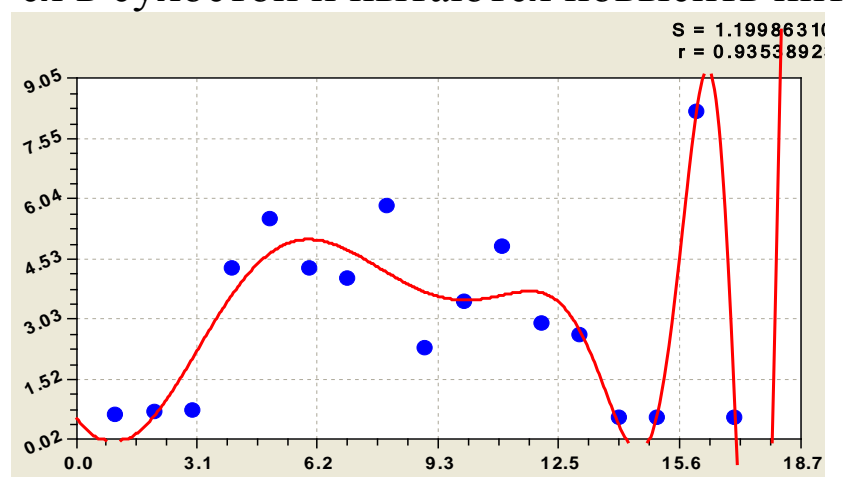

Рис. 4. Ранговое распределение параметра $a_{1}$

Из графиков на рисунке 5 видно, что каждая волна имеет четкие границы изменения по рангам дендрометрических рядов. Поэтому возможен анализ амплитудно-частотной характеристики (АЧХ) каждого вейвлет-сигнала.

Можно по остаткам искать новые члены - настолько чувствителен к методу анализа вейвлетов [3, 4, 10] интенсивность роста сосен в высоту.
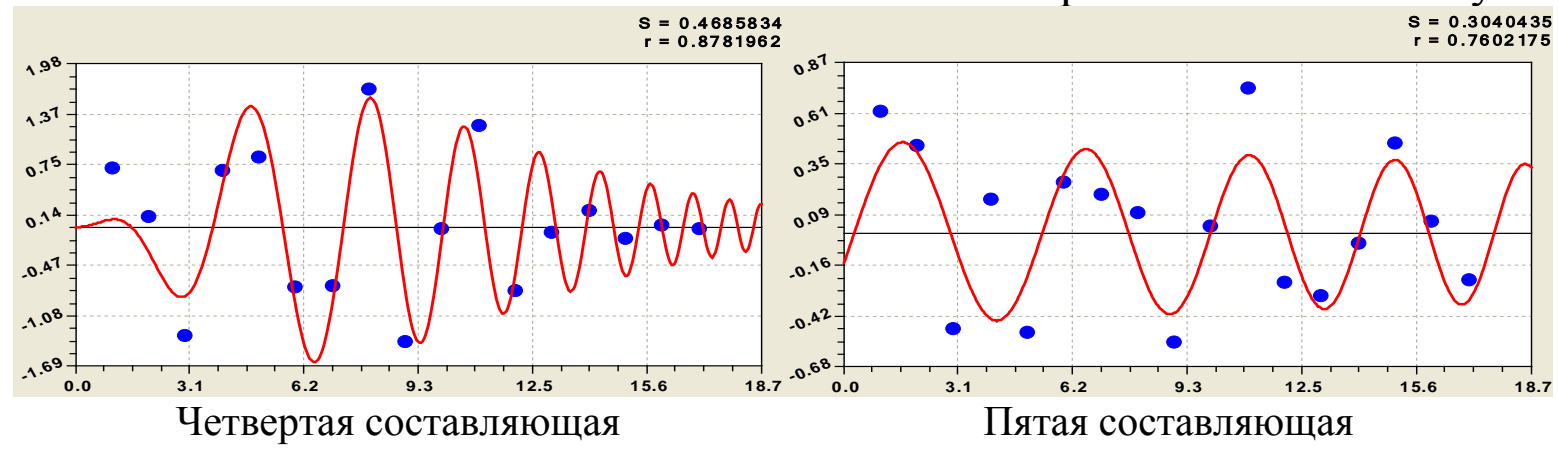


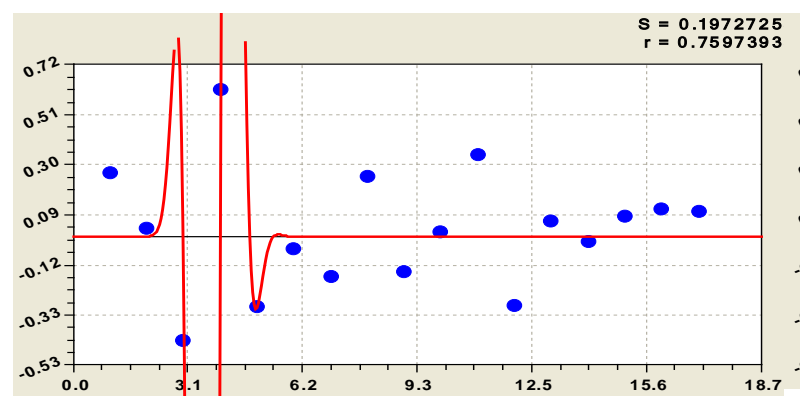

Шестая составляющая

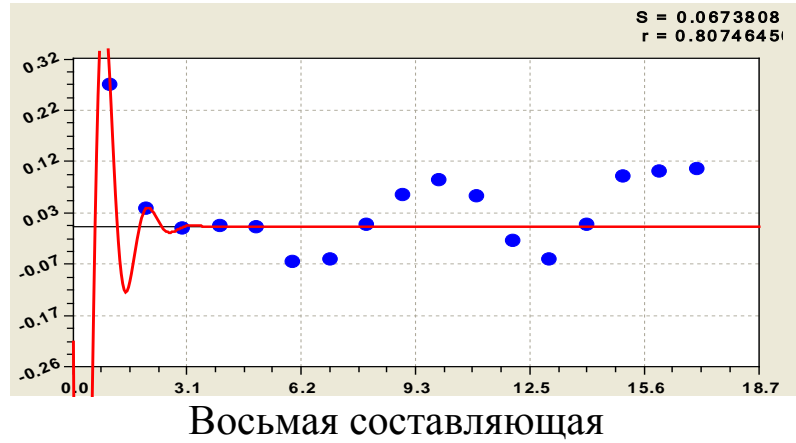

Восьмая составляющая

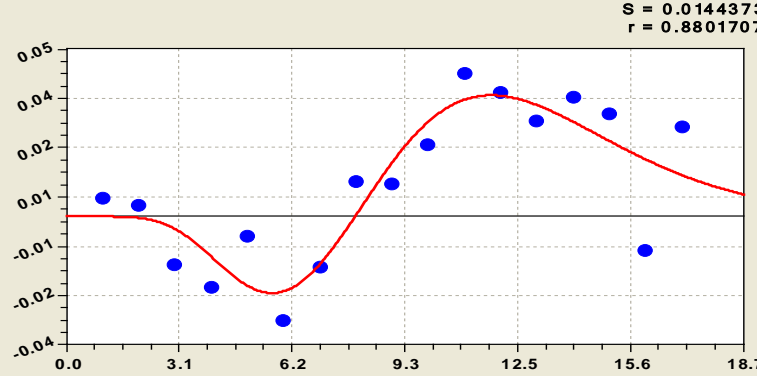

Десятая составляющая

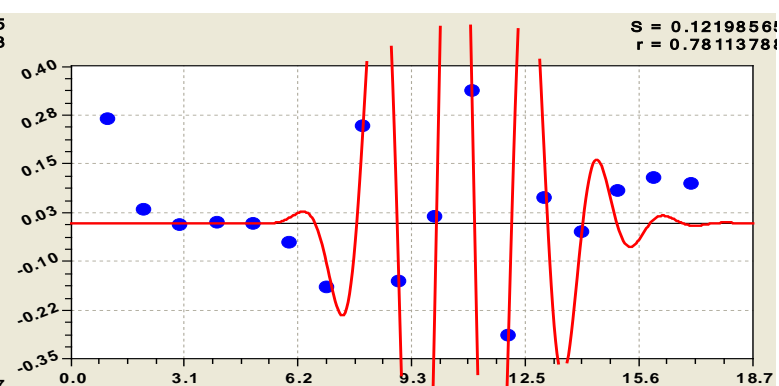

Седьмая составляющая $S=0.0298952$
$r=0.8941164$

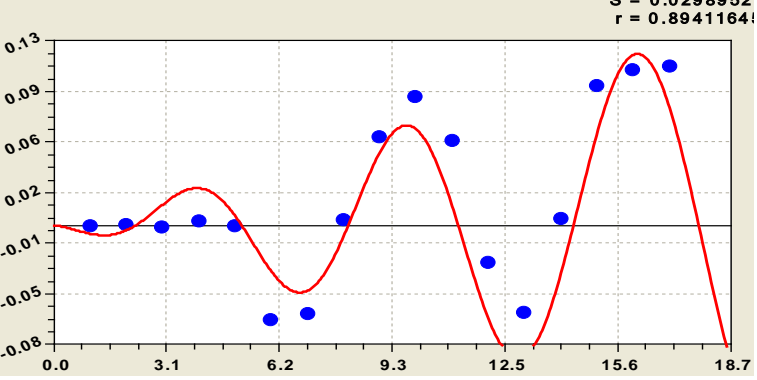

Девятая составляющая

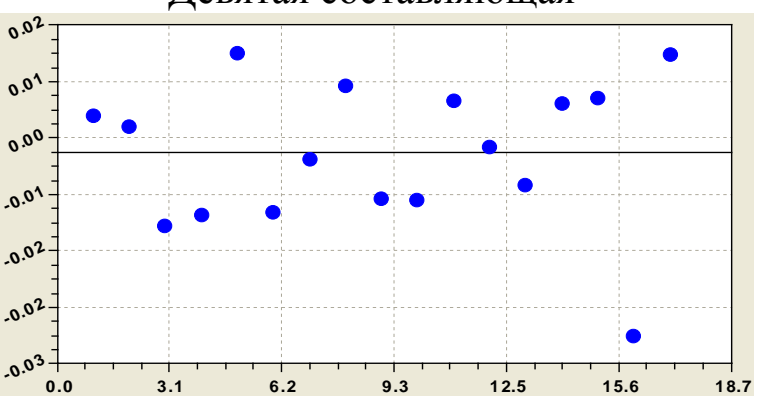

Остатки после 10-ого члена модели (3)

Ри.унок 5. Дополнительные закономерности рангового распределения параметра $a_{1}(1)$

Активность гибели сосен. Параметры $a_{1}$ и $a_{2}$ дают показательный рост сосен в высоту от его толщины, а параметры $a_{3}$ и $a_{4}$ характеризуют гибель 219 сосен. В таблице 5 дана волновая динамика (рис. 6 и рис. 7) показателя $a_{3}$.

Активность гибели очень высока у произрастающих деревьев.

Таблица 5

Параметры волнового уравнения (3) распределения 18 дендрорядов по активности $a_{3}$ спада высоты ствола у 203 модельных и 16 сухостойных сосен

\begin{tabular}{|c|c|c|c|c|c|c|c|c|c|}
\hline \multirow{2}{*}{$\begin{array}{l}\text { № } \\
i\end{array}$} & \multicolumn{4}{|c|}{ Амплитуда колебания } & \multicolumn{4}{|c|}{ Полупериод и сдвиг колебания } & \multirow{2}{*}{$\begin{array}{l}\text { Коэфф } \\
\text { коррел }\end{array}$} \\
\hline & $b_{1 i}$ & $b_{2 i}$ & $b_{3 i}$ & $b_{4 i}$ & $b_{5 i}$ & $b_{6 i}$ & $b_{7 i}$ & $b_{8 i}$ & \\
\hline 1 & 29776584,0 & 12,81019 & 21,95659 & 0,29844 & 0 & 0 & 0 & 0 & \\
\hline 2 & $-1,02298 \mathrm{e} 10$ & 28,52829 & 27,84533 & 0,52331 & 36,68621 & 0 & 0 & $-1,30258$ & \\
\hline 3 & $-3,41106 e-17$ & 15,38716 & 0 & 0 & 1155,2617 & $-58,71982$ & 1 & $-4,40853$ & \\
\hline 4 & 1,10103 & 0,86400 & 20063 & 1 & 0,25671 & 0,099524 &, 90179 & 1,03866 & \\
\hline 5 & 0,011511 & 2,09584 & 0,0024393 & 2,42737 & 2,26624 & $-0,11106$ & 0,81432 & 3,09400 & 0,8718 \\
\hline 6 & $6,79709 \mathrm{e}-10$ & 18,63127 & 2,29450 & 0,99816 & 0,27702 & 5202 & 00194 & 0,84466 & \\
\hline 7 & $2,09305 \mathrm{e}-62$ & 84,69171 & 5,91980 & 1 & 0,11622 & 0,040594 & 1 & 5,33316 & 0,7937 \\
\hline 8 & $-0,14975$ & 1,72070 & 0,70284 & 0,99939 & 05031 & $-0,0018651$ & 1,08854 & 2,16201 & 0,8381 \\
\hline 9 & $-2,02829 \mathrm{e}-11$ & 29,04642 & 4,97918 & 0,99543 & 11,12283 & $-0,75360$ & 1,04241 & $-1,44549$ & 0,7306 \\
\hline 10 & 1,65682e-9 & 11,94714 & 1,01886 & 1,01878 & 2,85591 & $-0,042136$ & 1,09768 & 0,42385 & 0,7153 \\
\hline 11 & $-0,038398$ & 1,93502 & 0,70916 & 0,96949 & 14,28801 & $-0,53589$ & 1,08360 & $-0,29454$ & 0,722 \\
\hline
\end{tabular}




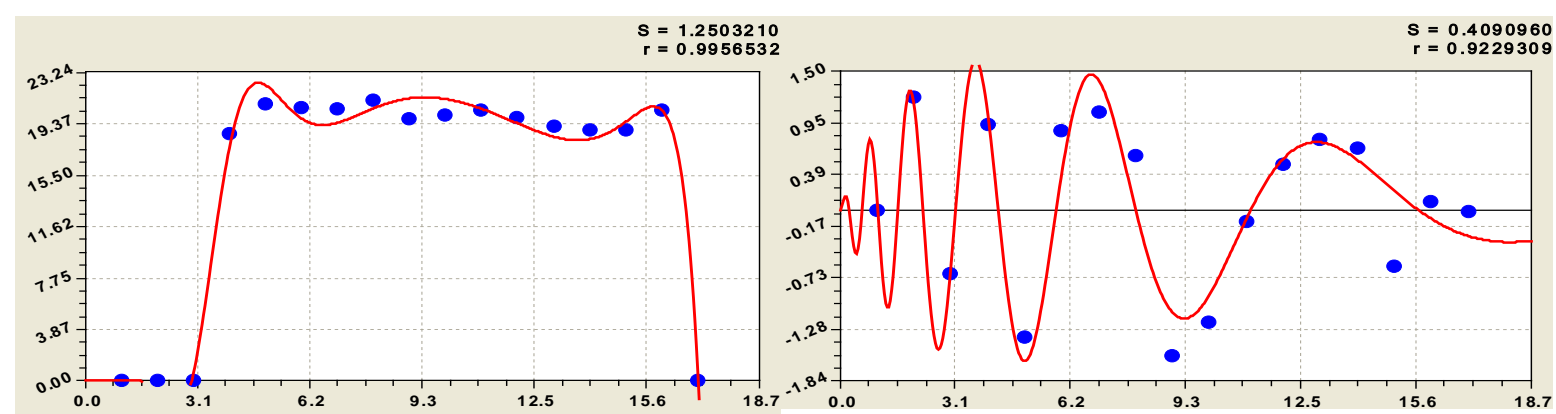

основная трехчленная закономерность четвертая составляющая общей модели (3)

Рисунок 6. Графики первых четырех составляющих рангового распределения параметра $a_{3}$

Деревья-лидеры оказались вне конкуренции за высоту произрастания, поэтому они имеют малые значения параметра модели (1) $a_{3}$. У сухостойных сосен она также мала, но они еще имеют какой-то процесс жизнедеятельности. Это четко показывает четвертая составляющая (рис. 6), когда колебательное возмущение успокаивается, по мере увеличения ранга дендрорядов, то есть частота колебания высоты сосен рядов снижается.

Адекватность каждого члена из 11 составляющих модели (3) высокая, так теснота факторной связи выше 0,7 (сильные факторные связи). Поэтому в дальнейшем можно проводить анализ динамики каждого вейвлет-сигнала по амплитуде и частоте отдельного колебания.

Интенсивность гибели сосен. Параметр $a_{4}$ дает скорость гибели 219 сосен, из которых к моменту измерений 16 уже стали сухостойными, но, как мы полагаем, они биологически не совсем погибли.

В таблице 6 дана волновая динамика (рис. 8 и рис. 9) интенсивности $a_{4}$.

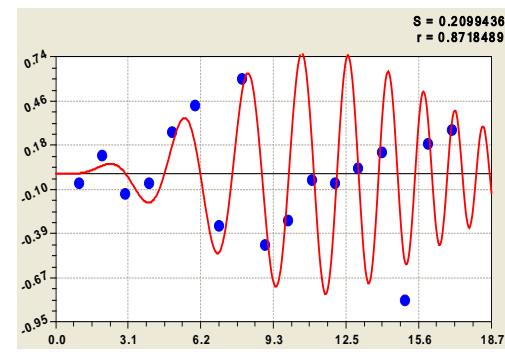

пятая составляющая

$S=0.0394922$
$r=0.8381404$

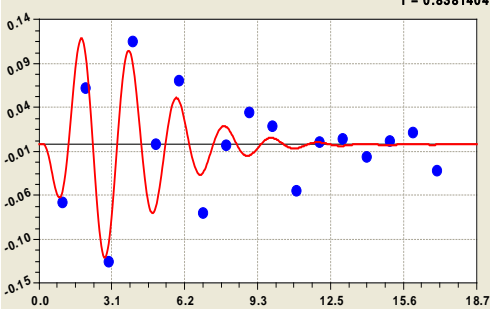

восьмая составляющая

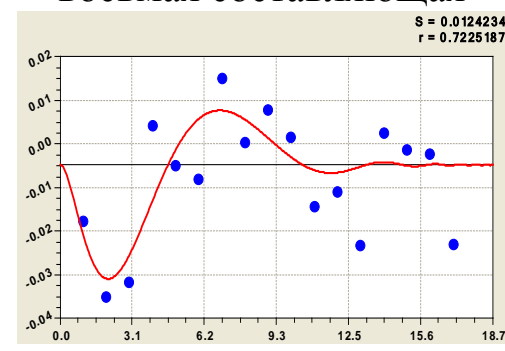

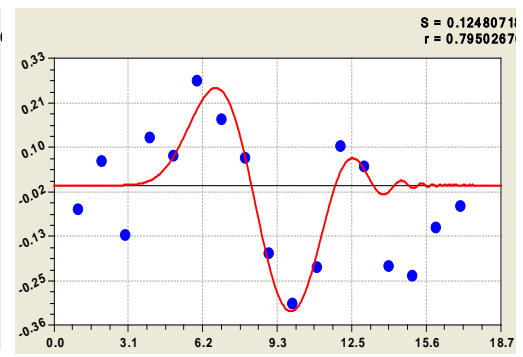

шестая составляющая

$s=0.0269417$
$r=0.7305931$

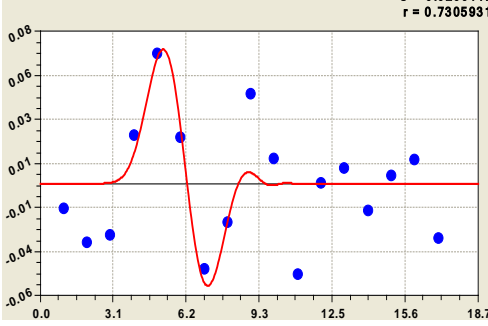

девятая составляющая

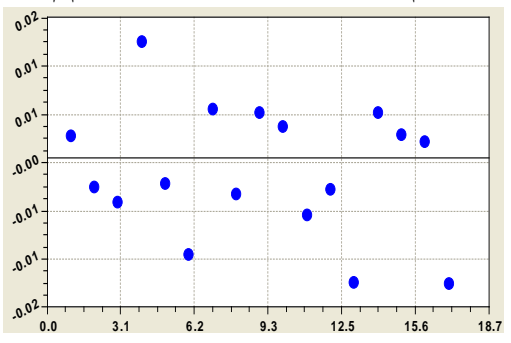

$\mathrm{S}=0.0661295$
$\mathrm{r}=0.7936943$

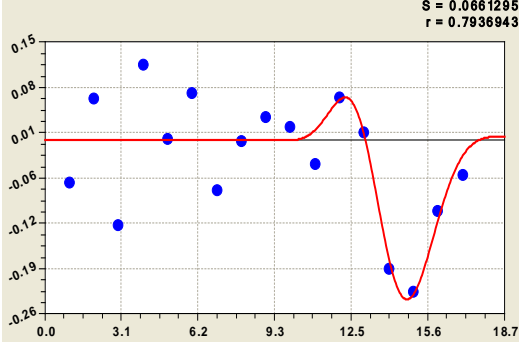

седьмая составляющая

$\mathrm{S}=0.0185244$
$\mathrm{r}=0.715289$

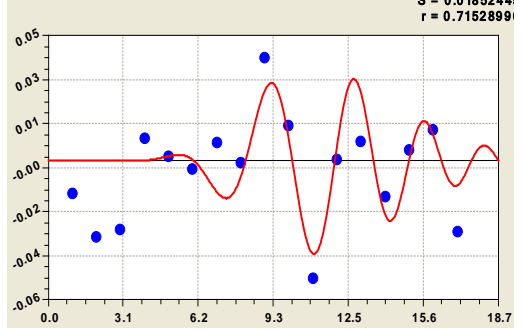

10-ая составляющая

Остатки после 11-го члена позволяют продолжать идентификацию волновой функции (3), но необходима специализированная программная среда для достижения «эффекта встряски» при совместном моделировании всех членов 
11-ая составляющая остатки после 11-го члена (3) волновой функции (3)

Рис. 7. Ранговые волновые распределения параметра $a_{3}$ модели (1) 18 дендрорядов сосен

Таблица 6

Параметры волновой функции (3) распределения сосен 18 дендрорядов

по интенсивности $a_{4}$ биотехнического закона (1) спада высоты ствола

\begin{tabular}{|c|c|c|c|c|c|c|c|c|c|}
\hline № & \multicolumn{4}{|c|}{ Амплитуда колебания } & \multicolumn{4}{|c|}{ Полупериод и сдвиг колебания } & \multirow{2}{*}{$\begin{array}{l}\text { Коэфф. } \\
\text { коррел. }\end{array}$} \\
\hline$i$ & $b_{1 i}$ & $b_{2 i}$ & $b_{3 i}$ & $b_{4 i}$ & $b_{5 i}$ & $b_{6 i}$ & $b_{7 i}$ & $b_{8 i}$ & \\
\hline 1 & 1 & 0 & 0,23157 & 1 & 0 & 0 & 0 & 0 & \multirow{3}{*}{0,9897} \\
\hline 2 & $1,47113 e-37$ & 30,99689 & 0 & 0 & 0 & 0 & 0 & 0 & \\
\hline 3 & $-0,048167$ & 11,86882 & 3,45529 & 1 & 0,81703 & 0,093730 & 1,49421 & 2,96126 & \\
\hline 4 & 0,0011789 & 1,57075 & 0 & 0 & 3,79930 & 0 & 0 & 3,10567 & 0,5300 \\
\hline 5 & 6,48961 & 1,81523 & 3,01521 & 1 & $4, .06389$ & 0,079238 & 1,22726 & $-0,096922$ & 0,8933 \\
\hline 6 & $-1,96471 \mathrm{e}-7$ & 15,57872 & 2,18363 & 0,98981 & 1,10230 & $-0,0063944$ & 0,99582 & 0,38762 & 0,8566 \\
\hline 7 & 0,00036216 & 3,77970 & 0,49547 & 0,98064 & 3,30785 & 0,27348 & 1,03825 & 0,79982 & 0,7085 \\
\hline 8 & $-6,87962 e-13$ & 8,78486 & 0 & 0 & 1,92360 & $-0,0074468$ & 1,06116 & 3,04442 & 0,9216 \\
\hline 9 & $8,44004 \mathrm{e}-5$ & 3,92957 & 0,46288 & 1,02262 & 2,25665 & 0,0015016 & 1,12916 & $-0,34682$ & 0,8825 \\
\hline
\end{tabular}

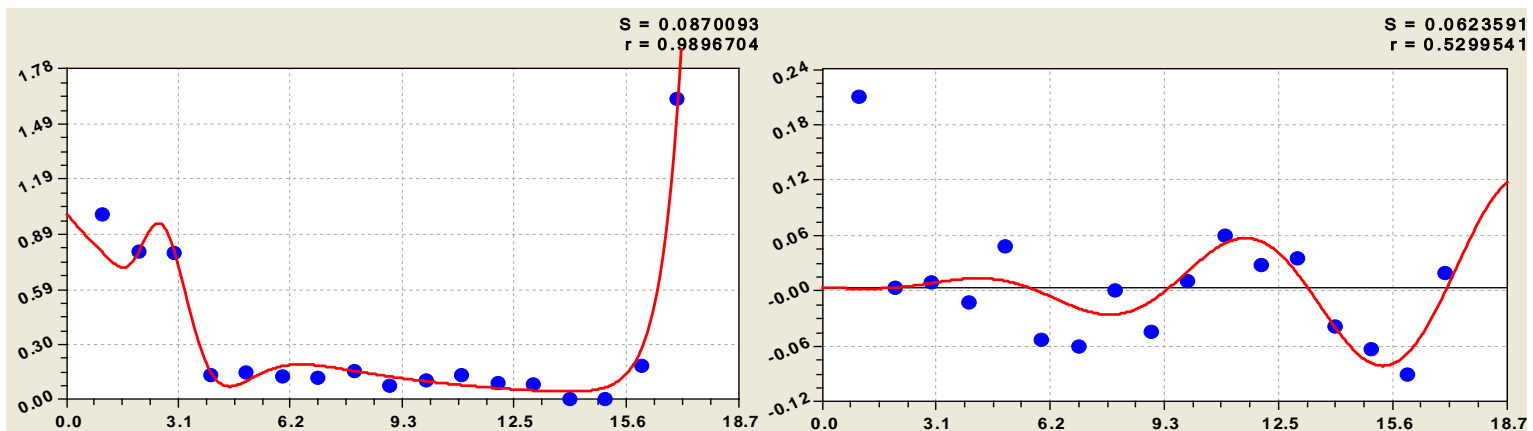

основная трехчленная закономерность четвертая составляющая общей модели (3)

Рисунок 8. Графики первых четырех составляющих рангового распределения параметра $a_{4}$

Первые три члена дают основную биотехническую закономерность. Остальные шесть членов дают всего $13 \%$ от максимума $a_{4}$. Однако малые колебательные возмущения дают возможность соснам адаптироваться к среде.
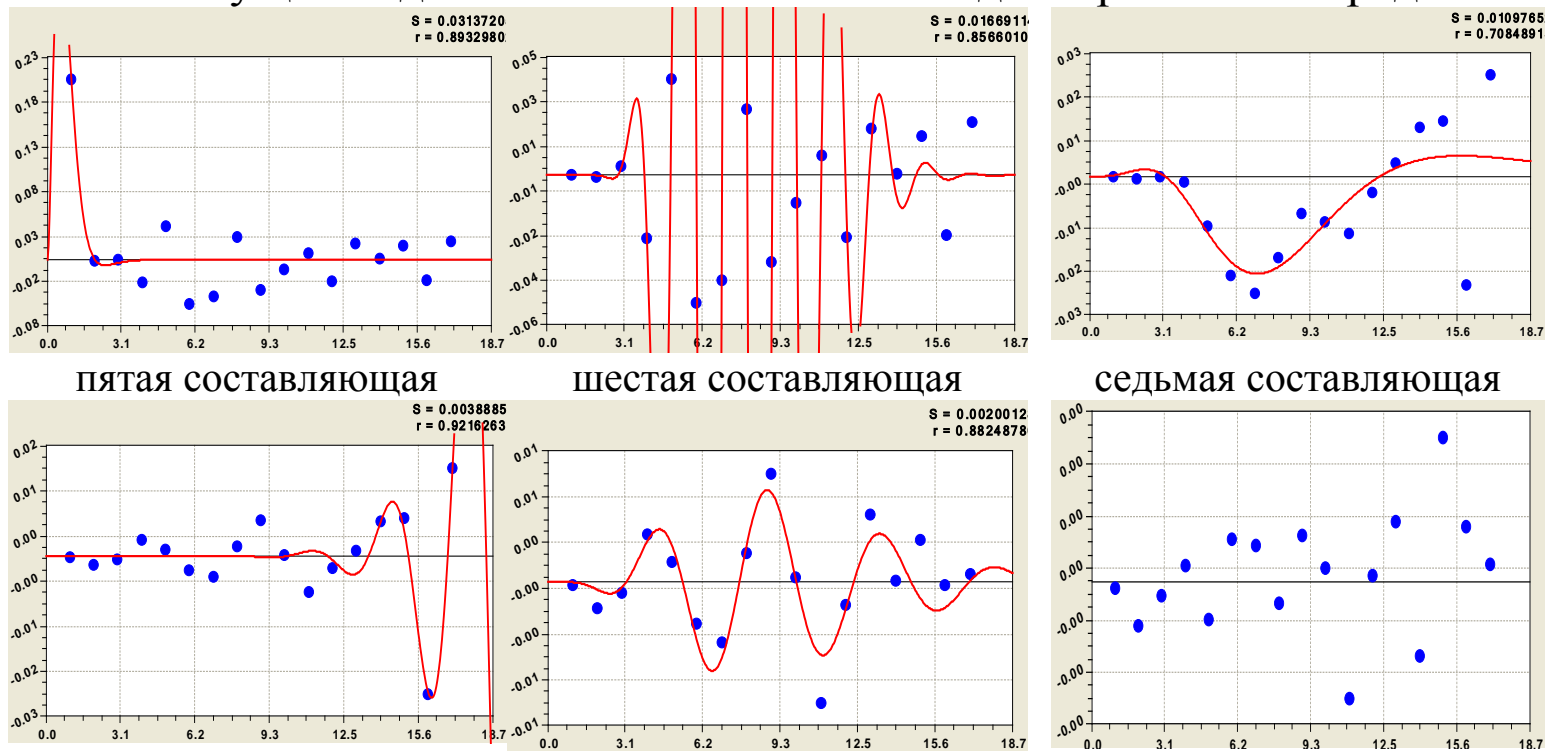

шестая составляющая

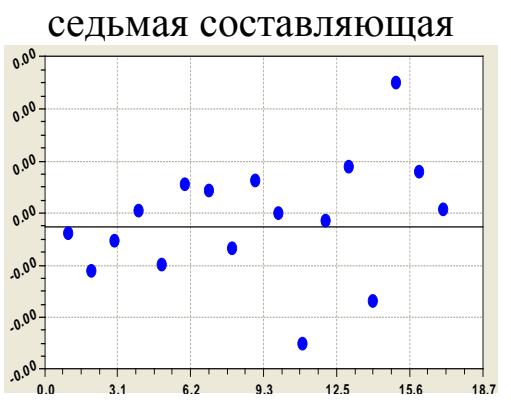

восьмая составляющая

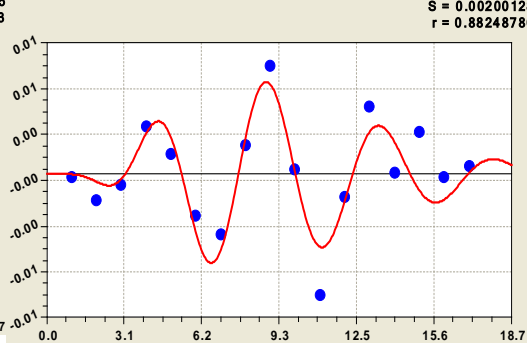

девятая составляющая

остатки после 9-го члена (3)

Рисунок 9. Дополнительные ранговые волновые распределения параметра $a_{4}$ модели (1)

Таким образом, с учетом переменных параметров модель (1) имеет вид: 


$$
H_{c}=a_{1}(p) D_{1.3}^{a^{a_{2}(p)}} \exp \left(-a_{3}(p) D_{1.3}^{\kappa}{ }^{a_{4}(p)}\right) .
$$

В модели кривой высот 219 сосен пробной площади находится, по данным таблиц 3-6, всего $5+10+11+9=35$ волн колебательного возмущения.

\section{СПИСОК ЛИТЕРАТУРЫ}

1. Мазуркин П.М. Дендроряды разновозрастного сосняка по кривым высот // Междисциплинарные исследования в области математического моделирования и информатики / Материалы 4-й научно-практ. internet-конф. Отв. ред. Ю.С. Нагорнов. Ульяновск: Изд-во SIMJET, 2014. С. 122-130.

2. Мазуркин П.М. Базовые критерии управления лесами и лесопользованием // Вестник УМО по образованию в области природообустройства и водопользования. 2011. № 3. С. 310-330.

3. Мазуркин П.М. Биотехнические закономерности таксационных показателей пробных площадей // Матер. междунар. конф. «Международное сотрудничество в лесном секторе: баланс образования, науки и производства» (3-5 июня 2009). Йошкар-Ола: МарГТУ, 2009. С. 84-87.

4. Мазуркин П.М. Принцип экосистемной суперпозиции: группировки диаметра ствола модельных сосен из лесных культур Волго-Вятского региона // Леса России в XXI веке: материалы шестой междунар. науч.-техн. интернетконф., март 2011. СПб.: ЛТА, 2011. С. 121-136.

5. Мазуркин П.М., Бедертдинов Э.Н., Русинова Н.В. Оценка компонентного неравновесия древостоя по кривым высот и диаметров растущих деревьев // Успехи современного естествознания. 2009. № 8. С.23-32.

6. Мазуркин П.М., Долгих М.В. Компонентное равновесие и устойчивость древостоя. Йошкар-Ола: МарГТУ, 2011. 164 с.

7. Мазуркин П.М., Иванова Н.С. Оценка экологической устойчивости древостоя // Лесное хозяйство. 2009. № 4. С.21-22.

8. Мазуркин П. М., Михайлова С.И. Территориальное экологическое равновесие $=$ Territprial ecological balance: аналит. обзор; Учреждение Рос. акад. наук Гос. публич. науч.-техн. б-ка Сиб. отд-ния РАН, М-во образования и науки Рос. Федерации Федер. Марийс. гос. техн. ун-т. Новосибирск : ГПНТБ СО РАН, 2010. 430 с. (Сер. Экология. Вып. 94).

9. Мазуркин П.М., Светлакова Е.В. Экологическая оценка территории по ведомости перечета деревьев на лесосеке / П.М. Мазуркин, Е.В. Светлакова // Лесоэксплуатация: межвуз. сб. научн. тр. Вып. 5. Красноярск: СибГТУ, 2004. C.77-82.

10. Мазуркин П.М., Степкина Е.А. Экологическое равновесие древостоя. М.: Изд-во «Академия естествознания», 2009. 240 с.

RANK DISTRIBUTION SETTINGS CURVES FOR HEIGHTS DENDRO-SERIES MULTI-AGE PINE FORESTS OF SIBERIA

(C) 2015 
P.M. Mazurkin, Doctor of Technical Sciences, Professor, Academician of the Russian Academy of Natural Sciences and the Russian Academy of Natural Sciences, Member of the European Academy of Natural Sciences,

Volga State Technological University (Yoshkar-Ola), Russia, kaf_po@mail.ru 